\title{
Subthreshold resonance in biophysically-based models of low- and high-input conductance motoneurons
}

\author{
Vitor M Chaud*, André F Kohn
}

From 24th Annual Computational Neuroscience Meeting: CNS*2015

Prague, Czech Republic. 18-23 July 2015

Resonance in the membrane potential enables a neuron to discriminate its inputs on the basis of their frequency content, so that oscillatory inputs near the resonant frequency produce the largest responses [1]. Recently, Manuel et al. [2] have shown that spinal motoneurons (MNs) exhibit membrane resonance in the frequency range of about 8-14 Hz. Modeling studies of resonance in neural membrane usually use minimal or reduced models, accounting only for the ionic currents sufficient to generate the resonance and plausible to exist in the investigated neuron type. However, in the present study we developed models of low- and a high-input conductance
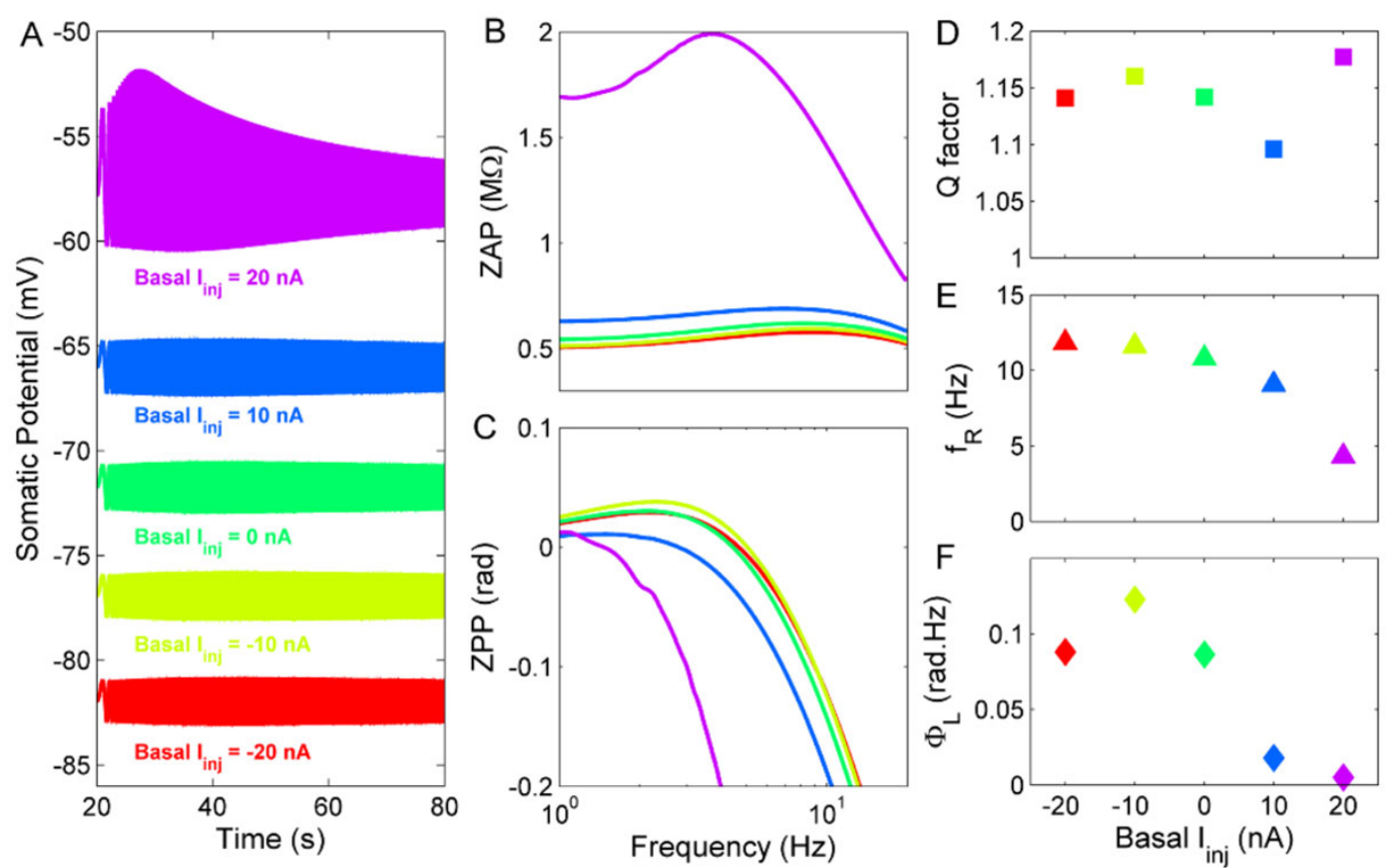

Figure 1 Dependence of resonance of the high-input conductance MN model on the basal level of injected current. A. somatic potential B. impedance amplitude $\mathbf{C}$. impedance phase $\mathbf{D}$. Quality $(\mathrm{Q})$ factor $\mathbf{E}$. resonance frequency $\left(\mathrm{f}_{\mathrm{r}}\right) \mathbf{F}$. total phase advance $\left(\Phi_{\llcorner}\right)$.

\footnotetext{
* Correspondence: vitor@leb.usp.br

Biomedical Engineering Laboratory, Dept. of Telecommunication and Control Engineering, University of São Paulo, São Paulo, SP, 05508-900, Brazil
}

(c) 2015 Chaud and Kohn This is an Open Access article distributed under the terms of the Creative Commons Attribution License (http://creativecommons.org/licenses/by/4.0), which permits unrestricted use, distribution, and reproduction in any medium, provided the original work is properly cited. The Creative Commons Public Domain Dedication waiver (http://creativecommons.org/ publicdomain/zero/1.0/) applies to the data made available in this article, unless otherwise stated. 
MNs including most of the ionic currents known or hypothesized to exist in mammalian MNs and exhibiting several of the known physiological features. Therefore, instead of investigating resonance as an isolated phenomenon we analyze it as consequence of interactions between the passive properties and the ionic currents in a more realistic fashion. The low-input conductance MN model did not show resonances, whereas the high-input conductance MN model showed resonances dependent on the membrane potential (Figure 1). These resonances were mainly caused by the hyperpolarization-activated cationic $(\mathrm{H})$ current. However, for membrane potentials near the firing threshold (purple lines in Figure 1), another resonance mainly affected by transient sodium and delayed rectifier currents predominated and its resonance frequency was correlated with the minimum firing rate caused by a step current injection.

\section{Conclusion}

These results contribute to the understanding of the complex interactions between active and passive properties in MNs and how these interactions can produce membrane potential resonance and affect action potential generation. The relation we found between subthreshold resonance and the minimum firing rate merits further studies to better understand how firing rate may be affected by membrane resonances.

Published: 18 December 2015

\section{References}

1. Hutcheon B, Yarom Y: Resonance, oscillation and the intrinsic frequency preferences of neurons. Trends in Neurosciences 2000, 23:216-222.

2. Manuel M, Meunier C, Donnet M, Zytnicki D: Resonant or not, two amplification modes of proprioceptive inputs by persistent inward currents in spinal motoneurons. J Neurosci 2007, 27:12977-12988.

doi:10.1186/1471-2202-16-S1-P129

Cite this article as: Chaud and Kohn: Subthreshold resonance in biophysically-based models of low- and high-input conductance motoneurons. BMC Neuroscience 2015 16(Suppl 1):P129.

\section{Submit your next manuscript to BioMed Central} and take full advantage of:

- Convenient online submission

- Thorough peer review

- No space constraints or color figure charges

- Immediate publication on acceptance

- Inclusion in PubMed, CAS, Scopus and Google Scholar

- Research which is freely available for redistribution

Submit your manuscript at www.biomedcentral.com/submit 